\title{
ResearchOnline@JCU
}

This is the author-created version of the following work:

McDowall, Ailie (2020) Layered spaces: a pedagogy of uncomfortable reflexivity in Indigenous education. Higher Education Research \& Development, . (In Press)

Access to this file is available from:

https://researchonline.jcu.edu.au/63106/

(C) 2020 HERDSA

Please refer to the original source for the final version of this work:

https://doi.org/10.1080/07294360.2020.1756751 


\title{
Layered spaces: A pedagogy of uncomfortable reflexivity in Indigenous education
}

\author{
Ailie McDowall \\ ${ }^{a}$ Indigenous Education and Research Centre, James Cook University, Townsville, Australia \\ ailie.mcdowall@jcu.edu.au
}

https://orcid.org/0000-0002-4737-3563 


\title{
Layered spaces: A pedagogy of uncomfortable reflexivity in Indigenous education
}

\author{
Univeristy disciplines are grappling with how best to incorporate Indigenous content and \\ frameworks for practice into their teaching to better prepare graduates to work with \\ Indigenous communities. Yet the pedagogical approaches that can best engage students in \\ Indigenous Studies as a field of critical study are still being debated. This paper has two \\ aims. The first is to consider how an uncomfortable reflexivity may provide an alternative \\ theoretical and methodological approach to preparing university students for future work. \\ This reflexive approach is an alternative to frameworks such as transformative learning. \\ The second aim is to consider Nakata's cultural interface as a teaching tool that may open \\ discussion around how professionals embody the disciplinary histories that govern their \\ work.
}

To do so, I present the writing of a pre-service teacher undertaking a professional experience placement and her engagement with the cultural interface to make sense of her experiences within the classroom. The cultural interface is used to analyse both the engagements between teachers and students, as well as presented as an analytical framework that can be taught to students to prepare them to engage in complex and contested Indigenous spaces.

Keywords: Indigenous education; Indigenous Studies; uncomfortable reflexivity; preservice teachers; teacher education; transformative learning; cultural interface

Across Australian higher education, universities are introducing Indigenous graduate attributes into degrees, Indigenising the curriculum, and incorporating Indigenous practice frameworks in applied disciplines such as medicine, social work, and psychology. In education, initial teacher education degrees are incorporating curriculum content to ensure that graduating teachers meet the Australian Professional Standards for Teachers (APST; Australian Institute of Teaching and Learning [AITSL], 2014) which focus on "strategies for teaching Aboriginal and Torres Strait 
Islander students" (Focus area 1.4) and "understand and respect Aboriginal and Torres Strait Islander people to promote reconciliation between Indigenous and non-Indigenous Australians" (Focus Area 2.4).

Despite education's potential to shift tertiary students' thinking around Indigenous affairs and Indigenous knowledges, the increasing introduction of and focus on Indigenous content, knowledge, perspectives and pedagogies in these disciplinary fields is not an innocent move. Nor are these fields neutral territories. This paper is a re-puzzling of the role of the personal in the Indigenous Studies higher education space, using teacher education as a case to consider how we can continue to "think what we do" (Kameniar, Windsor \& Sifa, 2014, p. 114) as tertiary educators. All teaching requires representational practice, shaped by the teacher's understanding of a topic and their perceptions of students' understandings (Wineburg \& Wilson, 1991). As such, individuals must consider the responsibilities they hold for the depictions they construct. Uncomfortable reflexivity (Pillow, 2003) is a methodological approach researchers use to challenge their representation-making practices. Uncomfortable reflexivity could assist becoming-professionals to make sense of their own roles and responsibilities in working with Indigenous peoples; a more useful approach to teaching and learning than to promote the transformation of students.

\section{Teaching in Indigenous Studies}

Nakata, Nakata, Keech and Bolt (2012) call for educators to recognise the university discipline of Indigenous Studies as a complex theoretical space where all students can learn to "understand the conceptual limits of their own thinking" (p. 121), rather than asking non-Indigenous students to account for their social locations. This second approach reifies binaries between Indigenous 
and non-Indigenous, black and white, colonised and colonsiser. Such binaries are so omnipotent that it is difficult to think about teaching in Indigenous Studies without using categories such as Indigenous and non-Indigenous. In her paper on the limits of self-reflexivity, Carey (2015) builds on this argument to suggest that for non-Indigenous students, self-reflexivity is often represented "as uncritical deference to an always-unified Indigeneity" (p. 830). Such a move creates a homogenised and essentialised 'Indigenous identity'.

My main aim in this paper is to explore uncomfortable reflexivity as a possible approach for students of Indigenous Studies, in response to Nakata and colleagues' (2012) challenge to consider a pedagogical practice which encourages university students to open themselves up to the complexity of thought within Indigenous Studies. Here, I position uncomfortable reflexivity as a more useful pedagogical approach than frameworks such as transformative learning. As an analytical tool to promote such reflexivity, I use Nakata's (2007a, 2007b) cultural interface to understand the classroom as a site where Indigenous Studies takes place at both secondary and tertiary levels, drawing on primary data from a research project on pre-service teachers' experience of a compulsory subject focused on Indigenous education.

I use the terms 'Indigenous Studies', 'Indigenous education' and 'Indigenous perspectives' throughout this paper. Indigenous Studies refers to the "field of academic study and inquiry" (Nakata, 2004, p. 1) relating to Indigenous peoples; based predominantly in higher education spaces. Related teaching may come under the banner of Indigenous Studies, or through specialised subjects in applied disciplines (e.g. education, social work). Indigenous education-a discursive construction (Vass, 2012) — is used here to refer to both the teaching of Indigenous students and Indigenous perspectives and/or knowledges within the curriculum at a school level. Indigenous perspectives is a broad term, referring to Indigenous worldviews, understandings, 
histories and analysis (Nakata, 2004; Thaman, 2003). Such perspectives are often in practice the meta-narratives about Indigenous people from non-Indigenous people controlling the representation of these narratives within schooling.

\section{A note to re/presentation}

This writing is a foray into a layered and complex knowledge space which is shaped and governed by disciplinary practices and historical circumstances, circumscribed by language, and underpinned by Indigenous agency (Nakata, 2007b). In the following passage, I grapple with the questions of representation that are implicated in all research. These questions are more prominent in research directly affecting Indigenous peoples, as research has been used as a tool to subject Indigenous peoples globally (Smith, 2009); and constructions of knowledge about Indigenous peoples have traditionally come from outside of Indigenous peoples themselves (Nakata, 2007a). The following passage uses creative analytical practice (Richardson, 1990) to enter into dialogue with other writers about the ways writing is implicated in the process of knowledge production.

Sipping my coffee, I ask, "So the representations we make of the people in our research can't claim to be a full representation of events that transpired?"

“That's right," Laurel affirms. "There are multiple ways in which representations will always be partial (Richardson, 1997, p. 43). Consider it-our work will only ever represent a very limited part of the object of study. To begin with, you yourself do not enter the research project as a blank slate. And perhaps even more interesting and less obvious are the ways in which our representations are often structured through metaphor: in science, we often 
talk about strong theoretical 'foundations', or comment on why a 'framework' has 'fallen apart', implying that theory is, in fact, a building (Richardson, 1997). These implicit metaphors orient and shape the knowledge we produce; shaping the underpinning philosophical values and directing how we make sense of data. Rather than trying to avoid metaphors, we can pay attention to how our writing always already uses rhetorical and literary devices, whose power we cannot ignore (Richardson, 2001, p. 879)."

"It's interesting that you mention power," I respond. "I moved in my research away from representing Indigenous students' experiences of higher education, because I haven't yet found a way to sit with the history of white researchers making claims to truth about Indigenous people as objects of research (Smith, 2009); inscribing Indigenous people into orders of knowledge that aren't their own (Nakata, 2007a), and the limitations of alternative modes of research production such as participatory approaches in really transforming power relations (e.g. Lather, 1988).

"But even now I struggle to work out how I am going to re/present the students whose journals I am writing about in my research. I've tried once in a conference presentation, and I ended up positioning my students as binary oppositions - 'good' or 'bad', as 'transformed' or 'not transformed'. The next time I saw them, I couldn't even look them in the eye. My research self is not separable from my lived self (Richardson, 2001, p. 879). But what is my 'research' if I'm not analysing the students' writing, if I'm not producing some type of finding about students and how they position themselves within Indigenous education?" Feeling flattened by this confession, I pause for a moment. "How do I weigh up the want and the need to produce findings in my research with not wanting to limit the people I work with in such categories?" 
“Well,” Laurel responds, “'Writing is never innocent. Writing always inscribes.'

(Richardson, 1997, p. 49)”.

This paper, too, is not innocent. It draws on research conventions such as the (re)presentation of empirical data to construct a particular version of knowledge about teaching and learning in Indigenous Studies, and a method section to make transparent to you the reader how I 'collected' this 'data' (authors such as St Pierre [1997; 2014, p. 10] challenge the normalising effects of privileging sets of texts known as 'data' over those determined as 'not data' - a dream, a movie script, a law). In this non-innocent writing move, I recognise that Indigenous researchers and knowers have long argued that the narrow version of 'valid' 'research'/'data' that is recognised within the Academy does not necessarily recognise their ontological, epistemological, and cosmological realities (Smith, 2009).

I also recognise that the language I use throughout this paper is problematic. What is Indigenous 'content', or 'perspectives'? These words are a poor substitute for the knowledges, understandings and experiences of First Nations peoples worldwide, already translated and circumscribed into a recognisable form by the disciplines (Nakata, 2007b). Lather (1988) uses the concept of a 'stuck place' to describe the impossibility of teaching critical pedagogy (given the knowledge and social structures we work within) as a place to learn. This paper, always already defined by the language and disciplines we each have access to, similarly begins from a stuck place. 


\section{The mirage of transformation}

A popular metaphor used in teaching Indigenous Studies (in both social sciences and applied disciplines such as education, health, and social work) is transformative learning. According to Mezirow (2003, p. 58), transformative learning "is learning that transforms problematic frames of reference...to make them more inclusive, discriminating, open, reflective, and emotionally able to change". In Australia, transformation has also been used to conceptualise and measure changes in (mostly non-Indigenous) university students' attitudes following Indigenous-focused coursework. Bullen and Roberts (2018), for example, used Mezirow's stage-based theory of transformative learning to measure change over time in first-year health science students' attitudes towards Indigenous Australians and towards Indigenous health as a priority, as well as readiness to work in health settings. Phillips and Archer-Lean (2018) argue for the transformative potential of an Indigenous standpoint-driven English Studies curriculum, whereby discussion of what it means to narrate stories and students' considerations of how their own standpoints influence reading can decolonise the discipline. Transformative learning has also been used to consider teacher education. Mackinlay and Barney (2014), for example, conceptualise transformation as holding potential as decolonising praxis, by engaging students in interrogating knowledge production about Indigenous peoples and questioning the ways in which they may unknowingly sustain racism.

Reflecting the metaphor of changing shape and form, Mezirow's (2003, p. 58) theory of transformative learning represents adult learners as holding "problematic frames of reference" from which an emancipated educator can liberate the student. Through a stage-based process, learners begin with a disorienting dilemma that leads to self-examination and a critical assessment of the self, leading to increasing confidence and competence in using more inclusive 
and discriminating frames of reference. Whilst some of the literature engages with this framework explicitly, and others use transformative learning as a more conceptual idea, I argue two issues. In doing so I am suggesting that the metaphor of transformation (a changing of shape) may instead be a mirage: an optical illusion of a desired and transcendent destination.

The first issue draws on Ellsworth's (1989) critique of critical pedagogy, an approach closely tied to transformative learning. Critical pedagogy cannot transcend an educational system that reinforces a hierarchy of power between teacher and learner. A critical pedagogy asks teachers and learners to engage as fully rational subjects, adding more knowledge to see the world 'more clearly', thus becoming more socially-just/anti-racist. Yet the same process of rational argumentation has been used historically to classify outside groups (Indigenous peoples, women, and others) as irrational. Similarly, transformative learning promises an end-point whereby students are transformed through a mode of rationalisation that helps them to see the world as it really is. This approach is attractive, promising a better future where 'problematic' students can be 'fixed'. The same approach has been critiqued in governmental and research approaches that seek to 'fix' the 'Indigenous problem', and instead fix Indigenous peoples as less-than non-Indigenous peoples (see, for example, Pholi, Black \& Richards's [2009] discussion of the Australian Commonwealth's campaign to Close the Gap). The focus on 'problems' begins from a construction of some as needing fixing; as inherently broken. The same logic that has been used to unjustly govern the lives of Indigenous peoples cannot be used to engage students in a discussion of justice.

The second issue, closely related, is that a focus on transformation as a pedagogical approach does not trouble the foundational belief that more knowledge doesn't necessarily shift deeply held epistemological beliefs. The inclusion of Indigenous content, either in specialised 
classes or embedded across a broader curriculum, can quickly be reabsorbed into the totality of the dominant knowledge approach. Bringing Indigenous content into curriculum requires bringing Indigenous knowledge into a cultural interface; a space already governed by competing and contested discourses about who Indigenous people are and the frameworks engaged to try to make meaning of the complexity of multiple world views, thought traditions, and ongoing and continuing coloniality (Nakata, 2011). This philosophical task exceeds asking students to have a 'better' worldview, or to be more receptive to the importance of Indigenous peoples, knowledges, and affairs in their future work. A graduate may leave university with a more receptive and less discriminatory frame of reference through which to understand 'Indigenous issues', but it does not follow that professionals will thus have the tools through which to engage multiplicity in the complex social, political and historical circumstances which impact Indigenous peoples' (and indeed all peoples') lives; let alone to recognise, enable and engage Indigenous agency in their future professions.

In teacher education, for example, an emphasis on the importance of understanding Indigenous students' positions in the classroom as historical subjects may translate to an essentialised view of Indigenous students' needs to meet a culturalised education. Such a view would ignore that Indigenous students are already accustomed to living and learning in an intercultural space, and instead may benefit more from learning language and frameworks to make sense of how their own lived experiences are situated within the classroom (Nakata, 2011). Instead, an approach of uncomfortable reflexivity - together with analytical tools to engage in the complexities within which people work-could structure our teaching. 


\section{Navigating the Interface}

The cultural interface may provide an analytical tool that students and educators can use to trouble the representations they make. In making sense of how we prepare university graduates to work with multiple knowledge systems, Nakata (2007b, p. 11) draws on the metaphor of "navigat[ing] the complexities of this contested space". The cultural interface- the spaces where Indigenous and non-Indigenous knowledge systems, ways of knowing the world, ontologies and cosmologies intersect, intertwine and contest each other-theorises the impacts of bringing Indigenous knowledges and positions into educational spaces that have been defined by Western traditions of thinking about the world (e.g. Nakata, 1998; 2007; 2011; et al., 2012). As universities and schools bring Indigenous knowledges, perspectives and standpoints into their curriculum, an act of translation is already in process. Such a process relies on the corpus, the "body of knowledge, both historical and ongoing, that is produced by others 'about us"” (Nakata, 2007b, p. 7). Originating from anthropology, the corpus also incorporates government and academic texts which have and continue to produce knowledge about 'who Indigenous people are'. The introduction of Indigenous knowledge or perspectives into a discipline means that what is re/presented to the students has been translated into what is allowed and deemed as acceptable by the discipline; by what is seen as relevant and what is irrelevant. The introduced ideas comprise the discursively ordered and organised corpus.

Various professions are embedding cultural perspectives and practices, possibly an effect of increasing numbers of Indigenous professionals occupying decision-making roles in these fields. Despite these shifts, there remains an epistemological divide in the practices of nonIndigenous Australians constructing who Indigenous people are, and how Indigenous people come to know themselves and their positions. Policies such as Closing the Gap, the predominant 
Indigenous policy approach from the Council of Australian Governments, permeate the broader public's imaginaries of who Indigenous people are through a discourse of statistical difference, disadvantage, and the need for the Australian public to lift Aboriginal and Torres Strait Islander people up (Pholi et al., 2009). Such discourses hark back to earlier government and education discourses of 'salvation'. The impact of such policies is that the only Indigenous person many non-Indigenous Australians know is the '5D Indigene': one defined by disparity, deprivation, disadvantage, dysfunction, and difference (Walter, 2016, p. 80). These discourses entangle Indigenous peoples in Western systems of knowledge.

Such discourses also shape the policies and practices within professions. The educational policy landscape across Australia is incorporating the importance of attending to Indigenous students, histories, cultures and societies in recognition of their status as First Nations peoples. These changes have taken place on a policy level through the introduction of specific standards in the APST (AITSL, 2014) and through state-based policies such as Queensland's Embedding Aboriginal and Torres Strait Islander Perspectives in Schools (EATSIPS; Department of Education and Training [DET], 2011). Initial teacher education programs across Australia have responded to this policy by, for the most part, introducing stand-alone compulsory subjects on Indigenous education (Moreton-Robinson, Singh, Kolopenuk, \& Robinson, 2012).

Whilst more Indigenous content is being embedded within the curriculum, different university disciplines have long been invested in developing knowledge about who Indigenous people are (Nakata, 2007a). Without troubling the epistemological frameworks into which this knowledge is added, the risk is run that it will be assimilated into both teachers' and students' ways of thinking about the world. 'Embedding' itself requires placing different parts into a whole: always already predicated on the idea of an essential Indigenous difference. The material 
and discursive spaces where learning takes place are already layered with histories and disciplinary practices which govern how these implantations and implementations - the embedding — can come to be.

\section{Drawing the threads together}

Teaching Indigenous Studies must engage students through analytical frameworks for understanding complex Indigenous/non-Indigenous relations (Nakata et al., 2012). Nonetheless, learning about Indigenous/non-Indigenous relations remains personal for many studentsIndigenous and non-Indigenous. Graduates will go on to work with Indigenous students, clients, patients, families and communities in contexts where Indigeneity has previously been (and to some extent continues to be) enacted as inferiority; and as such their own beliefs and the ways that they represent Indigeneity in their practice comes into question.

Students arrive at university having internalised the discourses repeated in households, schools, media and community. Some of these may include deficit perspectives; for others essentialised and romanticised notions of Indigeneity based on interpretations of anthropological texts; and yet others may hold complex understandings constructed through their own lived experiences, through family, work and/or social groups. Indigeneity is something that is always

already constructed and represented through historical and contemporary lenses, having meaning only "when understood in terms of intersubjectivity, when both the [Indigenous] and the [nonIndigenous] are subjects, not objects" (Langton, 1992, p. 32). The cohorts of students we teach are themselves a mixed, layered and entangled set of understandings, hopes, desires, fears and possibilities regarding issues covered in Indigenous Studies curricula. Many professions have fraught histories in relation to their treatment of Indigenous peoples. Given this, how students 
understand the impact they will have as graduates working with Indigenous peoples, knowledges and perspectives means that learning remains personal. In teaching Indigenous Studies, how do we take into account the tenacity of cognitive schemas that are used to understand the world?

\section{A re/presentation of a classroom}

Students require theoretical tools and language to engage with the complexity of Indigenous Studies and professional contexts (Nakata et al., 2012). Nakata's (2007a) theoretical framework of the cultural interface, the corpus, and the locale of the learner provide a way for researchers and educators to understand how university students and professionals may assimilate knowledge into unproblematised frameworks which create forms of ongoing epistemological and ontological violences. I propose that these concepts can be used to study the classroom as a locale which is constituted by such disciplinary knowledges. In this locale, Indigenous students enact agency informed by their location interfacing who they understand themselves to be, and their teachers' constructions of who they are. The third proposition is that the cultural interface can be taught to pre-service teachers and other tertiary students (Indigenous and non-Indigenous) as an analytical framework to move them towards an uncomfortable reflexivity; an interrogation of the representations they too may make as individuals.

The data presented here is derived from a recent research project exploring pre-service teachers' experiences of a stand-alone compulsory Indigenous education subject as part of a four-year initial teacher education degree in an Australian metropolitan university (see McDowall, 2018). Over a semester, students wrote weekly reflective learning journals as an assessment task (weighted at $30 \%$ of their total grade). This task was continued during a four week in-school teaching placement which took place in the middle of the semester. We asked 
students in the final weeks of semester for permission to use their journals for a research project, to which 93 students consented.

The writing I present here is from one student who I named "Macey" in my research. Macey was a third-year Bachelor of Education student who undertook her professional experience placement in regional North Queensland. I used Richardson's (2001) technique of writing a data narrative poem to re/present her experience in the classroom. Whilst Richardson (2011) uses data poems to draw out the poetry of spoken language, I have used a written journal passage. I left the bulk of the writing in the poem, using line breaks, repetition, font size, and page formatting to draw out the sound and sight (Richardson, 2011) of Macey's experience in class and to draw attention to particular moments; bringing the reader into the classroom space and emotion evoked by the reflection. Poetry-as-research and research-as-poetry is a reminder that there is no "one and only true story" which can be told via research; and instead, that all research representations are constructed knowledge recognised and validated by disciplinary conventions as claims to truth (Richardson, 2001, p. 879). Research-as-poetry alters our ways of hearing as readers.

In her reflective learning journal, Macey wrote at length about observing a secondary school classroom during her placement.

\section{Macey's Prac}

During the week I was observing a year ten social science class learning about Indigenous homelands. Studying Utopia in the Northern Territory.

There is a significant Indigenous population in the class. 
It was interesting

to interact with the class

to learn their diverse experiences with culture and perspectives.

The Indigenous students' knowledge ranged

from those that had been to homelands

had families on homelands

To those who knew nothing at all.

The non-Indigenous students lacked any knowledge

of Indigenous culture or traditions.

One student

begged my supervising teacher

not to watch the ABC 'Utopia' documentary.

He was aware of the current outcomes for Indigenous Australian peoples.

He was an Indigenous student himself.

He was deeply saddened by these realities.

My teacher had not adequately prepared the students for

the 'statistics'

that this young white female teacher

was simply displaying on a whiteboard.

The 'statistics'

that would ultimately shape

the lives of the young Indigenous people

sitting in front of her.

The unit relied on

students understanding

a deep spiritual connection to land

for Indigenous Australian peoples.

The non-Indigenous students struggled extensively to grasp this concept Such a foreign concept to students from other cultures.

Some Indigenous students identified immediately

With connection to land. 
Other Indigenous students

were somewhat stumped.

The teacher used "t h e y" and "u s".

"Connection to land

is part of who they are.

It's part of their spirit.

Their history.

Their culture."

“We don't share

the same connection to land".

The language upset me,

many of the students in the room being Indigenous.

You are either part of 'us'

or you are

one

One Indigenous student still struggled with the idea of an Indigenous connection to land.

The teacher suggested

"he might have had a more Western upbringing and therefore a Western perspective".

She then questioned the student's Aboriginality

asking

"Do you feel you've lost your identity

because you don't have a connection to land?"

A horrifying firsthand experience of

Nakata's (2012) story

where Indigenous Australian peoples

live in the complicated space

between Western academia and Indigenous culture. 
This teacher

has misinterpreted this space.

Assumed a deficit approach

Assumed that the student

had 'lost' his culture.

This teacher

missed an opportunity to build on Indigenous knowledge

(one or two of the Indigenous girls

had extensive knowledge of Homelands)

Missed an opportunity to stimulate and promote

Indigenous knowledge

ways of doing

acceptance in the classroom.

\section{The classroom as a discursive space}

In this piece of writing, Macey draws explicitly on Nakata's (2012) writing on the cultural interface, a set reading about living in-between teachers' expectations of how the corpus governed who Nakata was as an Islander and a student, and how he understood himself as an Islander and a student. Macey connected this theoretical perspective in her writing to her understanding of the classroom as a layered environment where the cultural interface was at play.

The teacher had tried to embed Indigenous perspectives into her teaching. Yet Macey's attentiveness to the resources used in her classroom (e.g. an extensive use of statistics, the documentary Utopia which showed the outcomes of generations of disastrous government policy in the remote community of Utopia in the Northern Territory; Pilger, 2013) and tropes of Indigeneity and identity showed an understanding of the corpus-in-play. These representationsan excessive focus on Indigenous people as remote and poor; Indigenous people living in cities having no cultural identity; Indigenous people as external to the classroom, reinforced with 'us' 
and 'them' language - constitute part of Macey's understanding of the discursive corpus that governs teachers' behaviours towards and about Indigenous peoples. This corpus works to constitute 'the real Aborigine': a representation of authenticity which allows a colonial society to maintain control over what does or does not count as Indigenous (Attwood, 1992). Images on the classroom projector, numbers and statistics written on a whiteboard, and words shared between teacher and student all contribute to a continuing living body of knowledge about Indigenous peoples, as governed by the rules of the classroom, the history of educational discourses, and the enactment of policies on the ground. Through this analysis, I seek not to censure the teacher's practices, but rather to move towards understanding how teachers embody disciplinary discourses in their teaching, and consider how teacher education may be able to provide alternative frameworks for students to better question how their own practices are tied into different discourses. Having learnt about the cultural interface in lectures, workshops and readings, Macey evoked the framework to make sense of the classroom she observed during her placement.

\section{The classroom as a locale}

The Indigenous students in this classroom, as represented by Macey in her writing, were agentic in their responses: the student speaking up was in a state of tension in what Nakata (2007b, p. 12) calls the "tug-of-war" between his own experience and the way that his teacher was positioning Indigenous peoples. Similarly, the student who was questioned as to his identity could be seen as having been caught between an Indigenous and non-Indigenous position, in a way that could be considered both epistemologically and ontologically violent. The reified binary of 
Western/Indigenous into which the teacher had incorporated the embedding of an Indigenous perspective limited how this student could be in the classroom.

\section{In contradiction of transformation}

It is worth noting that such a reflection does not suggest the end-point or having achieved a state of 'being transformed' (as transformative learning theories may suggest). In the next week's entry, Macey invoked her own tropes of Indigenous students based on Harris' $(1980 ; 1984)$ Aboriginal Learning Styles. Extending an argument that teachers can draw on students' 'strengths, interests and experiences', Macey wrote that 'Indigenous students prefer moving around doing hands on activities and working with classmates where they talk about their understanding'. The map of learning presented here is not linear. Even as Macey learnt to read the cultural interface of a classroom, critically reflecting on the enactment of the corpus, she continued to draw on other outsider theories of how Indigenous students learn; theories that promote an innate and biological idea of cultural difference. Another approach to understanding this learning process could be through reflexivity.

\section{The limits of self-reflexivity}

In her paper on the limits of a framework of cultural competency in higher education, Carey (2015) argues that the limits of self-reflexivity have seldom been engaged in the Indigenous Studies space. I would suggest that Macey's writing presents both possibilities and limitations of self-reflexivity as a learning device within Indigenous Studies. Through being asked to critically reflect on theory, observations, and her own shifting position as a becoming-teacher, Macey writes a critical understanding of the material and discursive spaces she will work within through 
the use of the cultural interface. Yet the limits to self-reflexivity are also clear: "sayings are not always doings" (Ahmed, 2004, para 52). Macey, as a pre-service teacher on her professional experience placement, constructed herself as an 'observer' in the classroom; a relationship with the class that left her unable to speak in this moment, only to write afterwards. Across the disciplines, students may have limited opportunity to enact different ways of knowing when working with Indigenous students, clients, communities, knowledges, and perspectives during their time as enrolled students. Relegated to the position of observer or encouraged to follow the book, disciplinary norms and every-day practices pull students' praxis back to the norms which constitute the status quo. Even as graduates, in-service professionals may have opportunities to integrate changes into their interpersonal practice, but may experience difficulty to implement new understandings on a larger scale whilst working under the practice frameworks of their employing body. Do understandings gained in universities translate to changed future practice?

In teaching, individuals will continually be required to make representations of Indigenous ideas in their praxis, whether in regard to the Indigenous students they teach or the perspectives that policies and the Australian Curriculum require to be part of their teaching for all students. The attention paid to both points has been hard fought for by Indigenous educators, parents and communities. I propose that a possibility of self-reflexivity could be found in Pillow's (2003) uncomfortable reflexivity: a reflexivity that knows that the representations we make in the construction of knowledge will always be imperfect, and that such representations are still necessary. This is about finding analytical tools that can help to push educators towards "an unfamiliar, towards the uncomfortable" (p. 192); and about recognising that as a society and a discipline we do not yet have the language or tools to find a pathway out of the complex relationship created by the colonisation of Indigenous peoples in this space known as Australia. 
Such an approach surpasses popular uses of self-reflexivity as a methodological tool. These include a recognition of the self; as a researcher (or educator) who is knowable and therefore can be liberated from one's own subjectivity. To stop at this point (of confessing one's own location in relation to the research) positions both the researcher and the researched as linear knowable subjects. As Spivak writes, "making positions transparent does not make them unproblematic" (1988 as cited in Pillow, 2003). The second approach is reflexivity as recognition of the other: practices such as 'giving voice', 'sharing data', and highlighting the ways that research subjects participate in the (re)inscriptions of their own selves. This reinvestment in the other-as-knowable masks how power is taken from research participants, rather than given to them: research reinvests in an unequal relationship which masks its own inequality. The third reflexive turn situates reflexivity as truth, as 'getting it right': practices of validity which seek to authorise texts. Such practices often operate within the regimes of truth (Foucault, 1977) that signify validity as a valid authorisation of research. Pillow (2003) argues that instead we could seek to make our processes of knowledge production better nuanced. The final approach to reflexivity is reflexivity as transcendence - a release from the weight of knowing that researchers and educators can only ever make representations which misrepresent, which bound others into a form of totality. The absolution of reflexivity-as-confession steadfastly holds true to Enlightenment beliefs in the power of truth and knowledge to free one's self. As an alternative to these practices, Pillow (2003) proposes a reflexivity of discomfort, which recognises that whilst all representations bring others into a construction of knowledge, questioning the personal in the formation of such representations can make us better accountable to "people's struggles for selfrepresentation and self-determination" (Visweswaran as cited in Pillow, 2003, p. 193). 
Pillow's (2003) arguments about reflexivity as a research praxis could be extended to educators, who also make representations about others and constructing knowledge about the world around themselves and their students. When embedding Indigenous perspectives into a classroom or university curriculum, or working with Indigenous students, educators are drawing on their own understandings of who Indigenous people(s) are. Educators embody the histories of Indigenous education, representations in anthropological texts, presence or absence within the media and popular culture of Australia, disciplinary practices around curriculum and pedagogy and government policies which layer into each other, producing the cultural interface of a classroom.

Nakata and colleagues (2012) call for educators to consider a pedagogical practice which engages students in Indigenous Studies as a critical field of learning, rather than in personally accounting for their social position. This argument has been rephrased as considering the limits to a self-reflexive approach (Carey, 2015). Yet individuals do hold, embody, and construct discourses about Indigeneity. As such, working with Indigenous peoples, communities and representations still requires interrogation of our beliefs. Uncomfortable reflexivity, based on an ethical accountability to the people and knowledges whom we work with and represent in teaching, can be a pedagogical approach to extend the limits of self-reflexivity. When combined with analytical tools such as the cultural interface, an uncomfortable reflexivity could help students-as-becoming-professionals to understand how they sit within disciplinary practices and policies; and navigate to a more careful approach of working with Indigenous ideas, perspectives and peoples. By re-framing students' personal positioning as shaped by disciplinary approaches, rather than an accountability based purely on their social location, the ways that all studentsIndigenous and non-Indigenous-work within this complex space comes under careful 
interrogation, without holding students personally to account for historical and political contexts. The introduction of uncomfortable reflexivity into this approach reminds us that individuals create ongoing historical and political contexts, and that there remains the possibility to work differently in Indigenous fields.

Providing educators with tools which open up multiple epistemological frameworks and asking them to remain personally accountable to the representations they make may assist in moving towards a praxis of accountability. For the question remains: How do educators teach Indigenous Studies, embed Indigenous perspectives, and engage with holders of Indigenous knowledge, knowing that given the ways that histories and disciplinary practices discursively constitute these spaces we may never be able to quite get it right, but that we may be able to get it more differently nuanced? 


\section{Acknowledgements}

Thank you to Dr Vincent Backhaus, Vicky Nakata and two anonymous reviewers for comments on earlier drafts of this paper, and the James Cook University CASE Research Seminar Series for an invigorating discussion around the ideas presented here. Finally, a big thank to you to Dr Liz Mackinlay for your guidance through the process of collecting and analysing this data, and all you have taught me, which is more than could ever be listed here.

\section{Funding}

There are no funding sources to disclose.

\section{Disclosure statement}

No potential conflict of interest was reported by the author. 


\section{References}

Ahmed, S. (2004). The non-performativity of anti-racism. borderlands e-journal, 5(3). Retrieved from http://www.borderlands.net.au/

Attwood, B. (1992). 'Introduction', in power, knowledge and Aborigines. Journal of Australian Studies, 15, ix-vi.

Australian Institute for Teaching and School Leadership [AITSL]. (2014). Australian professional standards for teachers. Retrieved from https://www.aitsl.edu.au/australianprofessional-standards-for-teachers

Bullen, J. \& Roberts, L. (2018). Driving transformative learning within Australian Indigenous Studies. The Australian Journal of Indigenous Education, 48(1), 12-23. doi: $\underline{10.1017 / \text { jie. } 2017.40}$

Carey, M. (2015). The limits of cultural competence: An Indigenous Studies perspective. Higher Education Research \& Development, 34(5), 828-840. doi:10.1080/07294360.2015.1011097

Department of Education and Training. (2011). Embedding Aboriginal and Torres Strait Islander Perspectives in schools: A guide for school learning communities. Brisbane, QLD. Retrieved from http://indigenous.education.qld.gov.au/SiteCollectionDocuments/eatsipsdocs/eatsips_2011.pdf

Ellsworth, E. (1989). Why doesn't this feel empowering? Working through the repressive myths of critical pedagogy. Harvard Educational Review, 59(3), 297-325. doi: $10.17763 /$ haer.59.3.058342114k266250 
Foucault, M. (1977). Discipline and punishment: The birth of the prison (A. Sheridan, Trans.). London, UK: Allen Lane, Penguin.

Harris, S. (1980). Culture and learning tradition and education in Northeast Arnhem Land. Darwin, NT: Northern Territory Department of Education.

Harris, S. (1984). Aboriginal learning styles and formal schooling. The Aboriginal Child at School, 12(4), 3-23.

Harrison, N. \& Greenfield, M. (2011). Relationship to place: positioning Aboriginal knowledge and perspectives in classroom pedagogies. Critical Studies in Education, 52(1), 65-76. doi: $\underline{10.1080 / 17508487.2011 .536513}$

Kameniar, B., Windsor, S. \& Sifa, S. (2014). Teaching beginning teachers to 'this what we are doing' in Indigenous education. The Australian Journal of Indigenous Education, 43(2), 113-120. doi:10.1017/jie.2014.27

Langton, M. (1992). "Well, I heard it on the radio and I saw it on the television...": An essay for the Australian Film Commission on the politics and aesthetics of filmmaking by and about Aboriginal people and things. North Sydney, NSW: Australian Film Commission.

Lather, P. (1988). Feminist perspectives on empowering research methodologies. Women's Studies International Forum, 11(6), 569-581. doi:10.1016/0277-5395(88)90110-0

Mackinlay, E. \& Barney, K. (2014). Unknown and unknowing possibilities: Transformative learning, social justice and decolonising pedagogy in Indigenous Australian Studies. Journal of Transformative Education, 12(1). 54-73. doi:10.1177/1541344614541170

McDowall, A.M. (2018). Following writing around: encountering ethical responsibilities in preservice teachers' reflective journals in Indigenous education (Unpublished doctoral dissertation). The University Of Queensland, St Lucia, Australia. 
Mezirow, J. (2003). Transformative learning discourse. Journal of Transformative Education, $1(1), 58-63$.

Moreton-Robinson, A., Singh, D., Kolopenuk, J., \& Robinson, A. (2012). Learning the lessons? Pre-service teacher preparation for teaching Aboriginal and Torres Strait Islander Students. Report published by the QUT Indigenous Studies Research Network, Brisbane, QLD, October 2012.

Nakata, M., Nakata, V., Keech, S. \& Bolt, R. (2012). Decolonial goals and pedagogies for Indigenous studies. Decolonization: Indigeneity, Education \& Society, 1(1), 120-140.

Nakata, M. (1998). Anthropological texts and Indigenous standpoints. Australian Aboriginal Studies, 2, 3-12.

Nakata, M. (2004). Indigenous Australian studies and higher education (Wentworth Lecture). Canberra, ACT: Australian Institute of Aboriginal and Torres Strait Islander Studies. Retrieved 19 November, 2019, from https://aiatsis.gov.au/sites/default/files/docs/presentations/2004-wentworth-nakataindigenous-australian-studies-higher-education.pdf

Nakata, M. (2007a). Disciplining the savages: Savaging the disciplines. Canberra, ACT: Aboriginal Studies Press.

Nakata, M. (2007b). The cultural interface. The Australian Journal of Indigenous Education, 36(s1), 7-14. doi:10.1017/S1326011100004646

Nakata, M. (2011). Pathways for Indigenous education in the Australian curriculum framework. The Australian Journal of Indigenous Education, 40, 1-8. doi:10.1375/ajie.40.1 
Nakata, M. (2012). Better: A Torres Strait Islander's story of the struggle for a better education. In K. Price (Ed.), Aboriginal and Torres Strait Islander education: An introduction for the teaching profession (pp. 81-93). Cambridge, UK: Cambridge University Press.

Phillips, S.R. \& Archer-Lean, C. (2018). Decolonising the reading of Aboriginal and Torres Strait Islander writing: reflection as transformative practice. Higher Education Research \& Development, 38(1), 24-37, doi:10.1080/07294360.2018.1539956

Pholi, K., Black, D., \& Richards, C. (2009). Is 'Close the Gap' a useful approach to improving the health and wellbeing of Indigenous Australians? Australian Review of Public Affairs, $9(2), 1-13$. Retrieved from http://www.australianreview.net/journal/v9/n2/pholi etal.html

Pilger, J. (Producer). (2013). Utopia [DVD]. Murrarie, QLD: Antidote Films

Pillow, W. (2003). Confession, catharsis, or cure? Rethinking the uses of reflexivity as methodology in qualitative research. International Journal of Qualitative Studies in Education, 16(2), 175-196. doi:10.1080/0951839032000060635

Richardson, L. (1990). Narrative and sociology. Journal of Contemporary Ethnography, 19(1), 116-135. doi: $\underline{10.1177 / 089124190019001006}$

Richardson, L. (1997). Fields of play: Constructing an academic life. New Brunswick, NJ: Rutgers University Press.

Richardson, L. (2001). Poetic representation of interviews. In Gubrium, J. F., \& Holstein, J. A. Handbook of interview research (pp. 876-891). Thousand Oaks, CA: SAGE
Publications. doi:10.4135/9781412973588

Smith, L.T. (2009). Decolonizing methodologies: Research and indigenous peoples (2nd ed.). London, UK: Zed Books. 
St Pierre, E.A. (1997). Circling the text: Nomadic writing practices. Qualitative Inquiry, 3(4), 403-417.

St. Pierre, E. A. (2014). A brief and personal history of post qualitative research: Toward "post inquiry." Journal of Curriculum Theorizing, 30(2), 2-19.

Thaman, K. (2003). Decolonising Pacific Studies: Indigenous perspectives, knowledge and wisdom in higher education. The Contemporary Pacific, 15(1), 1-7.

Vass, G. (2012). 'So, what is wrong with Indigenous education?' Perspective, position and power beyond a deficit discourse. The Australian Journal of Indigenous Education, 41(2), 85-96. doi:10.1017/jie.2012.25

Walter, M. (2016). Data politics and Indigenous representation in Australian statistics. In T. Kukutai, \& J. Taylor (Eds.), Indigenous data sovereignty: Towards an agenda (pp. 79108). Canberra, ACT: ANU Press.

Wineburg, S. \& Wilson, S. (1991). Subject-matter knowledge in the teaching of history. In J. Brophy (Ed.). Advances in research on teaching: Volume 2. Teachers' knowledge of subject matter as it relates to their teaching practice (pp. 305-348). Greenwich, CT: JAI Press. 